\title{
SYSTEMIC CHANGE AND ASSET SPECIFICITY THE CASE OF TRANSFORMATION IN CENTRAL AND EASTERN EUROPE*
}

\author{
B. DALLAGO \\ (Received: 5 March 2001; revision received: 20 July 2001; \\ accepted 3 September 2001)
}

\begin{abstract}
The economic system exerts its influence over the economy through many assets that are system-specific. Economic actors invest in such assets in order to capture the opportunities defined by the system. When systemic entrepreneurs set systemic transformation in motion, uncertainty is created. Together with externalities produced by investment in systemic transformation and the ensuing alteration of the property right structure, this determines the distribution of transformation costs and gains. This produces opportunities for investing valuable resources to weaken third-party enforcement and capture gains and avoid costs via transformational redistribution. This situation increases asymmetries, reduces the opportunities for productive outcome, and makes change costly and path dependent. This framework is used to explain the process of change in Central and Eastern Europe.
\end{abstract}

Keywords: economic system, transformation, system-specific assets, path dependence.

JEL classification index: D23, P31, P51.

\section{INTRODUCTION}

The purpose of this paper is to propose a testable explanation of why actors in modern, complex economies under transformation may not follow strategies converging toward the implementation of what appear to be the most efficient economic system. The latter is usually sketched in the reform blueprint. When change is so wide and deep that it involves the complexity of economic relations and the nature of actors, the crucial variable of analysis is the economic system. A system

* The research on which this paper is based has been financially sponsored by the Italian Ministry for the University and Scientific-Technological Research (MURST).

Correspondence: B. Dallago, University of Trento, Department of Economics, Via Inama 5, 38100 Trento, Italy. E-mail: bdallago@risc1.gelso.unitn.it 
can be defined as "a group or combination of interrelated, interdependent, or interacting elements forming a collective entity" (Collins Dictionary of the English Language). Such elements, in the case of an economic system, are institutions.

Three conditions are necessary for a set of institutions to form an economic system. First, they must structure the complex of social interaction in the economic domain. Second, economic actors should share the knowledge and acceptance of these institutions by free will, tradition or force. Third, these institutions must be co-ordinated.

Within an economic system, different institutions complement and strengthen each other in a characteristic way. Since institutions come in clusters within each economic system, they show complementarities and indivisibilities, each institution takes advantage of the network effects of other institutions and they show incompatibilities and trade-offs with different (clusters of) institutions. In this sense, the economic system shares the features of hayekian order, in particular a distinct pattern of relationships among the constituent elements that makes the outcome of co-ordination predictable. This gives the system an evolving stability that persists until shock does not promote change. However, as I will show below, stability means neither that systemic evolution is necessarily sufficient to adapt to environmental change, nor that the system is inevitably efficient.

An economic system presents many advantages for actors operating in the economy. In fact, the economic system gives order to human interaction, reduces uncertainty, diminishes transaction costs and the costs of conflicts, and addresses the activity of actors in a particular direction. The advantages of the economic system come at a price, though. Actors are required to invest valuable resources to adapt to and operate in that particular system. This investment is individually productive, because it gives individual actors the chance to profit from the opportunities and advantages that the system creates. The investment forms a value in the form of systemic capital that actors do not want to lose when the system changes. This influences the actors' (bounded) rational behaviour and choice. This investment is also socially productive, since it gives stability and predictability to economic interaction; thus it decreases the costs of interaction, simplifies and makes more effective the actors' cognitive processes and computational ability. This investment also supports the solution of problems of collective action by limiting the number and domain of economically feasible solutions, and strengthens the actors' co-operation and co-ordination in their effort to find new solutions to economic problems.

Contrary to the normal situation sketched above, there may occur a situation where there is an opportunity to freely choose and implement a more efficient system. This is systemic transformation, which consists of general change of institu- 
tions and their co-ordination. ${ }^{1}$ This happens when social actors agree that the old system was undesirable because it was ineffective, or when change is imposed, such as, following military defeat. ${ }^{2}$ Yet, despite individual preference for change and social agreement on its necessity and even on the desirable system notwithstanding and in spite of large individual participation or the imposition by a powerful force of a supposedly superior economic system, each actor behaves in a conservative way. Spontaneous processes of systemic transformation and institutional engineering are consequently insufficient to produce a better economic system, ${ }^{3}$ unless these are coupled with other conditions. These include proper policies paying due attention to the complex co-ordination of institutions. This provides the economic system with the proper variable of analysis. Transformation in Central-Eastern Europe offers a particularly clear case to study these processes. $^{4}$

In the next section the relationship between institutions and the economic system will be investigated. I conclude that, in order to understand the processes of transformation, it is necessary to consider the complexity that the economic system constitutes the centre of analysis. Section 3 deals with the economic system, system-specific assets and the consequence of their existence on the economic actors. The section shows that boundedly rational actors have incentives to invest in system-specific assets and accumulate systemic capital. The latter influences the behaviour and choice of actors. As shown in section 4, systemic capital explains why inefficient economic systems can be stable and why systemic change meets with obstacles, even if there may be an apparent agreement to change. In section 5 I show that systemic inefficacy opens opportunities for systemic entrepreneurs, who may invest in systemic change and promote investment by imitators. If so, systemic transformation is set in motion. However, the owners' of old systemic capital also influence transformation. As I show in section 6, there is no guarantee that this will produce a better economic system. This is due to the presence of old systemic capital, that can support investment in transformational distribution and

1 I use the term change to denote the modification of the economic system in general. Such change may consist of progressive (evolution) or radical and general modification (transformation).

2 The classical cases are those of post-war Japan and Central Europe.

3 By better system I mean an economic system that is more efficacious than any other in pursuing the economic goals of a society. Cf. J. S. Berliner (1999). In a given environment, a more efficacious system is one that is the cause of higher economic performance than it could be achieved by using the same amount of actual or potential resources within a different system.

4 For simplicity, I will disregard here the disagreement existing in the use of terms. I will consider the terms "transition" and "transformation" as synonymous. 
is due to the costs of transformation and their allocation. These factors stress the crucial role of enforcement. These costs are discussed in section 7 that shows how these and transitional distribution are the causes of path dependence of systemic transformation. Section 8 concludes the paper by discussing some conditions for transformation resulting in a better economic system.

\section{INSTITUTIONS AND THE ECONOMIC SYSTEM}

The economic performance of a country is determined by the economic system, together with policies and the environment within which economic activity takes place. ${ }^{5}$ The environment includes all those variables that influence economic performance, but are beyond the control of participants in the economy, such as culture, international geo-political situation, resource endowment, and level of development. Policies include variables that governments may influence in order to guide society towards reaching pre-set economic goals.

In this paper I give particular relevance to the economic system. The economic system consists of co-operating institutions that structure social interaction in the economic domain and whose knowledge and effect are shared by the members of the relevant society in their economic activity. The emphasis here is not only on the co-existence of formal and informal institutions, but also on the fact that these institutions form a cluster that is integrated and interdependent, and whose properties are known and whose effects are socially shared. This means that economically relevant institutions do not display their potential variety and variability, since these are those that respond positively to the framework of mutual influence, externalities and spillovers that the economic system materialises. Within a given economic system, each institution has a specific and well-defined character and is compatible with other institutions.

Focussing on the Soviet-type system, ${ }^{6}$ it is well known that one party in power and central planning are incompatible with efficient market institutions and behaviour. Consequently, money and prices have a passive role in the sense that they do not influence allocation and production decisions. Control and co-ordination are direct (political and administrative) in nature and require strong central government and passive firms.

5 For this important result of comparative economics cf. in particular T. Koopmans and J. M. Montias (1971). Cf. also G. Grossman (1974), S. H. Gardner (1998).

6 Cf. J. Kornai (1992). 
The Soviet-type system, as any other system, generates a characteristic regularity of behaviour of economic actors - individuals, enterprises and planners alike: the soft budget constraint that produces shortage. ${ }^{7}$ In the system, each institution presupposes the others and cannot survive if other crucial institutions are modified. Similarly, foreign institutions are rejected when introduced in an economic system. Economic reforms in Eastern Europe since Stalin's death supply abundant evidence of this fact. These particular relations among institutions form the core of the coherence of any viable economic system. This is not to say that systems cannot change. Indeed, they evolve. However, any successful evolution pays respect to systemic coherence and is consequently bounded by the existing features of the economic system. The alternative is disruption of the system and prolonged institutional instability: when even only one or a few crucial institutions are disrupted, others follow and lead to a general process of institutional and co-ordination disruption. Systemic transformation in Central and Eastern European countries was promoted and made inevitable by the devolution of the communist parties power and the following disruption of central planning. Obviously, this imposes limitations on the freedom of systemic arrangements that are viable, but also prevents systemic convergence. ${ }^{8}$

Since institutions are co-ordinated within the economic system, behavioural limitation and specialisation that they promote have a characteristic that is easily recognisable as belonging in a particular system. Such regularity of features and behaviour defines the type of relevant transaction costs and influences their size. These, together with other factors such as political interference and technology, determine the organisational forms that are possible, convenient or permitted in a given system and the economic behaviour that is (boundedly) rational. ${ }^{9}$

Consequently, systemic transformation not only changes the way actors play the economic game, it also alters economic actors. The game in the Soviet-type system consists of devising good central plans and implementing them in order to pursue collective goals (building socialism plus economic growth) that also produce individual benefits. In a market economy, the game consists of pursuing primarily individual goals (such as surviving competition and producing a profit) while paying due respect to social goals. Each game requires radically different kinds of behaviour of economic actors for which different economic actors are apt. Firms are radically different in the Soviet and in the capitalist systems, central planners having no role in the latter, as entrepreneurs in the former.

Cf. J. Kornai (1980).

Cf. the contributions included in B. Dallago (1999).

Cf. B. Dallago (2000a). 
The co-existence of formal and informal institutions opens a particularly complex aspect of the economic system and systemic transformation. ${ }^{10}$ An effective economic system is one where formal and informal institutions are properly integrated, so that they do not hamper but support and stimulate each other. This requires institutional adaptation, which is a crucial component of evolutionary processes. The co-existence of formal and informal institutions may be difficult and it is not clear in general terms which kind of institutions will adapt most. This depends largely on the features of the economic system.

For instance, according to the Bolshevik blueprint of the socialist society there was no room for private ownership, at least in the perspective of building communism. Agriculture was socialised and based on huge state and co-operative farms. Yet one of the most typical institutions of tsarist Russia, household plots, survived and flourished even in Stalin's Soviet Union. ${ }^{11}$ This obviously imposed an important adaptation also to "socialist" farms, a process that became one of the building blocks of the booming "second economy" in the Soviet Union and other Eastern European countries. ${ }^{12}$ Inevitably, the Soviet-type system that came out of this adaptation was different compared to the system envisaged by the cluster of formal institutions that Bolsheviks had in mind. Yet, individual formal and informal institutions were transformed and the new system was a peculiar arrangement that reflected the influence of both the original, formal blueprint and the informal traditions of Russia in a novel way. However, this does not necessarily mean that this peculiar arrangement is efficient in the given environment since the conflict between formal and informal institutions produce conflicting incentives. It certainly means that it influences the behaviour of economic actors differently.

Institutional economists are well aware that institutions of a different nature exist and that they form an (institutional) framework. However, the features of the latter are usually not considered further. This neglect is quite understandable methodologically, since it is supposed that institutions develop spontaneously or at least adapt, even when institutional change is part of government policies. Moreover, the core of institutional analysis is the capitalist firm in developed market economies, where the economic system is well established and only goes through incremental changes. Transaction costs economics, in particular deals with the economically most efficient allocation of organisational solutions in a world of positive transaction costs, boundedly rational and opportunistic actors and incomplete contracts. Property rights analysis derives consequences on eco-

10 On formal and informal institutions cf. S. Pejovich (1998).

11 Cf. A. Gerschenkron (1968).

12 G. Grossman (1977). 
nomic efficiency from the way in which property rights are allocated within firms. It is only when such rights are private, well defined and clearly enforced that actors have the certainty that they will collect the fruits of their investment, either directly or by selling their rights on the market. Hence their incentive to invest. Even scholars who pay particular attention to the "institutional framework", ${ }^{13}$ concentrate their interest on institutions rather than on the properties of distinct "frameworks".

These approaches are powerful in explaining economic performance in systemically stable contexts, yet they overlook the complexity of the co-ordination among institutions. They do not explain how a particular institutional framework developed, and they neglect the existence - even among developed capitalist economies - of roughly equally efficient (at least in the long run) economic systems. ${ }^{14}$ In short, they ignore the properties of the economic system.

Although the economic system has important consequences in normal circumstances, in particular circumstances its properties may become crucial and lead to consequences in contrast with the standard perspective. ${ }^{15}$ Transformation in Central-Eastern Europe is a textbook case, but both scientific debate and policy prescriptions largely overlooked the systemic perspective, even among comparative economists. The crucial debate in this case has been between "shock therapists" and "gradualists". ${ }^{16}$ The former approach maintains that a policy shock would induce actors to change and adapt by producing new institutions without major costs or other obstacles. In contrast, the latter supports the view that institutional change needs time to bring through a process of creative destruction. Advocates of the gradualist approach are based on the relevance of the past and suppose the existence of path-dependent processes. Yet, in this latter approach this is usually done at the micro-level, without paying sufficient attention to the economic system. In the former approach, although attributing great relevance to macroeconomic processes, the role of the economic system is totally disregarded. The features of the economic system are of major importance in order to understand the influence of individual institutions on economic performance. When particularly deep and far-reaching changes take place, the neglect of the economic system may prevent a correct understanding of processes - including institutional change - let alone devising proper policies.

13 Cf., e.g., D. C. North (1990)

14 The classical case here is that of Anglo-Saxon capitalism vs. continental European and/or Japanese capitalism.

15 The efficiency-enhancing consequences of ambiguous property rights in an economic system such as the Chinese one is a clear case in point. Cf. D. Li (1996).

16 For a criticism of this dichotomy cf. H. W. Hoen (1998) and J. Kornai (2000). 


\section{THE SPECIFIC NATURE OF SYSTEMIC ASSETS}

The role of the economic system in the economy is operationalised through a set of system-specific assets that consist in a particular nature and structure of information, knowledge and skills, interpersonal and inter-organisational relations, decision-making processes, possible and viable organisational solutions, features of technology and capital. Since operating in the framework of the existing economic system is economically advantageous, as explained in the previous section, agents acting with bounded rationality need to invest resources in system-specific assets and accumulate systemic capital in order to pursue their goals. Such investment, and the property over systemic capital deriving from there, influence behaviour, decisions and activity of actors. These are important factors, which explain the stability of economic systems. Since actors invested valuable resources and they own systemic capital and since any systemic transformation implies the need to invest resources in new system-specific assets and the loss of old capital, actors will not give up what they own, unless the existing economic system imposes costs and losses upon them that are greater than the value of their systemic capital. Under these circumstances, the system may survive well beyond its economic rationale.

Actors who operate in an economy are generally rational in the sense that they are interested in improving their individual position. However, this takes place among the constraints and co-ordination the system imposes upon their activity. Their rationality is bounded ${ }^{17}$ in the sense that they must take decisions having incomplete information and knowledge and limited computational ability. Due to the effect of the economic system and because of the bounds limiting their rationality, actors have to invest resources in order to learn the working of the economic system, set up proper structures to operate in that system and limit the bounds to their rationality. This is investment in system-specific assets, i.e. investment in the opportunity set defined by the system, either to adapt or to gain individual advantages or to oppose any unfavourable alteration of the distribution of assets or bargaining power and of relative value of resources. This is, in short, my explanation of the importance of the economic system for individual actors and of the stability of economic systems.

Asset specificity means that, when the economic system changes, assets cannot be redeployed to alternative uses and by alternative users at all or without major sacrifice of productive value. ${ }^{18}$ In an economy, the systemic specificity of some

17 On the definition of rationality see H. A. Simon (1990).

18 The concept of asset specificity is used, among others, by O. E. Williamson (1985), who traces back the use of the concept at least to Marshall's Principles. 
assets derives from the superior social and individual outcome coming from having a stable economic system. Since this gives order, co-ordination and predictability to economic interaction, the economic system allows control of opportunistic behaviour and the co-ordination of the activity of actors in lowering transaction costs, capturing network externalities and other advantages from co-operation and from operating on the bases of shared mental models. The economic system also facilitates and structures co-operation in analysing and explaining problems and discovering and implementing new solutions. There is a reason here for actors to invest in those assets that represent permanent features of the system and that are specific to that system, since such investment improves the actors' situation and strengthens their position within the system, as explained below. Once this investment is implemented, there is a permanent reason to keep the economic system in order to protect such investment from destruction or expropriation and from the predatory activity of opportunistic actors, and to protect the investment from any systemic transformation that would create major losses for investors. In fact, such destruction or expropriation not only would wipe out the actors' quasi-rents associated with the status quo, it would also destroy the ad- ditional individual and social value associated with the role of the economic system (in terms of lower transaction costs, predictability, discovery, etc.). One can largely explain transformational recession in Central and Eastern European countries with the destruction of (old) systemic capital.

In theory and in any economic system, asset specificity is defined by the rate of substitution of a given asset following the transformation of the economic system. Purely system-specific assets lose their productive value and investment, while general assets remain unaffected. In between the two extremes lies the potentially infinite number of real cases that consist of those cases when systemic change affects in some way and different measure the return to assets.

The degree of system-specificity and generality are, therefore, important features in defining the nature of the economic system and consequently the strategies and behaviour of actors. They also determine the fate of specific assets during and after systemic transformation.

Individual investment of resources in system-specific assets is a necessary condition to capture the net outcome that the economic system produces. It is the individual (or group) investment in system-specific assets of different actors (or the politically or socially motivated impossibility for some actors to perform such investment) that creates asymmetries of the actors' ability to influence the outcome of economic activity and get a return therefrom. This is so because such investment - that is the necessary condition for the economic system to work and produce its net outcome - allows to capture quasi-rents and determines the allocation of the costs of control, hence the net return to investment in general assets of each 
actor. In fact, since the latter cost is paid by those who are controlled, investment in system-specific assets also determines the return to general investment and consequently the incentives to production.

(Nearly) pure system-specific assets are rare, but may be important. Think of the activity of brokers in a capitalist economy and even more so capitalist entrepreneurs. These activities did not exist in the Soviet-type economic system - except in the underground economy. Equivalent functions - at least in the allocation of resources - were played by central planners and tolkach (informal input procurers) and the leaders of the party in power. Transformation made these roles and the relative specific investment and capital disappear. It should be noticed here that what is system-specific is the particular way in which a function (possibly of general nature, such as the allocation of resources) is implemented, the particular features of the actors who play such functions and the devices they use to reach such end.

On the other extreme, other assets are general, that is, their existence is independent of any particular system. This is a more theoretical than real category, since systemic transformation varies the relative value of nearly all assets. However, some kind of knowledge and skills (e.g. planning and building bridges, organising an army and fighting, teaching mathematics, electronic programming, cultivating the goodwill of superiors, knowing how to produce shoes or drive a truck) and the necessary physical assets are largely independent from the economic system (although not necessarily from the political system). When the system changes, their value is modified marginally, if at all. It is these investments that determine the performance of the economy within the boundaries set by the economic system in the given environment. General investment is not lost when the system is changed. Return to it may even increase, if systemic transformation improves co-ordination and incentives and diminishes the cost of control and enforcement by increasing the relative importance of general assets.

Asset specificity and generality are features that may even concern the physical aspect of assets (e.g. their size, as in the case of buildings, machines or plants). However, they reflect mostly the influence that the economic system has on the economic and possibly technical attributes of particular assets. This influence varies in degrees and is seldom absent or total. The Soviet-type system offered many and important examples to support this statement. For instance, although steel is not system-specific, there is no doubt that excessive steel production as was typical to Soviet-type economies were system-specific, as was the decision-making process related to steel production. Similarly, although employment is not system-specific, the impossibility for a firm to dismiss employees and other features related to labour organisation are system-specific. Let us consider a crucial actor as the firm. It has many assets that are general. These include such technical 
knowledge, together with machinery and equipment to cast iron, combine different elements to obtain alloys, produce a bicycle or a car, build a house, and so on. There are also such general features as some aspects of labour organisation within plants (e.g. workers allocated to machines according to their skills, engineers in technical planning offices) or the size of scale economies that are linked primarily to the existing technology. Systemic transformation alone has no or modest impact on features like these, except for the effect it may have through technical progress. In this case systemic transformation opens up the access to new sources of technology. But take the size structure and production profile of firms: in the Soviet-type system size was important while small and medium-size enterprises (SMEs) were virtually absent; profile was rigid and determined by administrative, not by economic considerations.

This was in reality a necessary condition for the proper working of the centrally planned system. Large scale went usually well beyond technically or productively optimal size and the production profile made technical progress difficult and discrete in nature. Such size structure and production profile included assets whose supply form can be considered system-specific, such as the firms sections dealing with personal services to employees (e.g. kindergarten or the procurement of consumption goods) and the offices dealing with the implementation of plan orders. These are respectively forms of adaptation to shortage and to planning and indeed these sections and offices disappeared from firms following transformation. By administrative decisions, firms included establishments located in distant places and producing different parts of the same good. This decision was generally not linked to economic considerations, such as proximity to input procurement or final market. This made transportation technically complex and costly. With the unfolding of transformation, many establishments became independent firms and trade flows often changed direction. Other system-specific assets had to do with the highly specialised production profile, the statutory monopoly of production, the administrative establishment and the bureaucratic survival of firms, the impossibility for firms to change production assortment or to sell or buy establishments or reorganise production. These aspects disappeared when free entry and exit were granted, firms were restructured and SMEs boomed.

The practice to implement very large investments, to give priority to heavy industry, to assign important job rights to employees, to carry out large part of foreign trade with other Soviet-type economies based on administrative approach, the costly and ineffective decision making and informational system, and forced growth supply other examples. All this required many devices that can be considered as system-specific assets (agencies for the collection and elaboration of information; offices for drawing up plans, define prices and allocate goods; control, enforcement and punishment structures; etc.) that further increased the large 
amounts of resources (time, energy, physical and financial resources) that individuals, organisations, and the state/party apparatus had to invest to govern the system. ${ }^{19}$ This had important consequences for the nature and behaviour of economic actors and for economic performance.

Similarly to the case of general investment, the accumulation of investment in system-specific assets produces systemic capital. This capital corresponds to the capitalisation of the return in monetary or financial terms, in terms of real privileges, bargaining power, prestige or other moral values, during the expected life of the economic system and discounted for the risk of expropriation or systemic transformation. In case of systemic evolution, such capital has a particularly long life and only requires minor, although continuous investment for adapting the systemic capital to the changes produced by systemic evolution. In case of systemic transformation, pure systemic capital is lost and a major discrete investment is needed in all other cases to adapt to systemic change.

Any system is endowed with system-specific assets. However, some systems, as with the Soviet-type system, need a relatively higher investment in system-specific assets compared to general assets than other systems. Although this is not necessarily synonymous of lower effectiveness, such greater investment derives from the pragmatic, non-spontaneous nature of the economic system, whereby designed formal institutions are imposed upon old formal and informal institutions. This may be done in order to reach a politically shared goal: e.g., a social revolution, the unification of a group of countries or two previously separated parts of a country (e.g. the European Union and the two former Germany or Vietnam). This may also be the goal of a powerful domestic or foreign agent who pursues his or her individual interest or a superior collective or public outcome: e.g. the SCAP in post-war Japan. When there is contrast between the two groups of institutions or formal ones are inconsistent, additional system-specific assets are needed to manage contrasts and inconsistencies and to reach co-ordination and integration. Consequently, actors have to invest additional resources in system-specific assets and

19 Although investment in system-specific assets is a normal feature of economic actors in a given system, it may be one of the motivations of vested interests. The latter is properly seen, in the framework presented here, as the concern that investors in system-specific or also general assets have in increasing the value of any investment by means of rent-seeking activities. However, to pursue their goal, individuals, or interest groups need to invest resources that are not part of investment in system-specific assets. This they can do by utilising their systemic or general capital to pursue quasi-rents. Thus vested interests explain return to general or specific capital that exceeds the return they would obtain in a competitive environment. Since the asymmetric ownership of systemic capital creates asymmetries of bargaining power, owners of systemic capital are likely to be relatively more successful in their effort than owners of general capital. 
systemic capital is relatively more important. However, this does not originate necessarily lower systemic effectiveness, since this depends on the particular nature of system-specificity and on the goals pursued through the economic system.

Systemic capital influences the behaviour and adaptation of actors and their learning and cognitive processes. This was true also in the Soviet-type economy, which was a shortage economy. In this particular environment, economic actors had to invest a great amount of resources to adapt. Among the many forms this investment took, one can mention queuing up efforts to join social networks, setting up unofficial workshops within plants, hiring hidden agents (tolkach) to produce or procure directly the needed inputs, goods and services. These were particularly costly undertakings that required among other things the acquisition of specific knowledge and skills and setting up specialised organisations. In this way, the shortage economy created informally new, valuable jobs and positions (for example, those of elderly people, who could stay in line also on behalf of other people in exchange for some reward, and of tolkach). The adaptation to the shortage economy also gave additional value to other jobs and positions, such as those of shopkeepers and waiters and in general of those dealing with the allocation and distribution of goods in shortage.

In the Soviet-type system the state budget centralised the income of firms and reallocated it to the same or other agents and activities. This required that firms invested resources trying to influence the process, often in a rent-seeking way. This influence was usually aimed at making the process of plan orders implementation easier or plainly at private gain. ${ }^{20}$ Consequently, the type of investment in system-specific assets having a strictly economic nature that was most costly was investment in the centrally planned system. ${ }^{21}$ The centrally planned system required, at the central level, the work of great numbers of people, offices, collection and elaboration of information for elaborating plans, transmitting orders and controlling implementation. It also imposed particular requirements to different offices (e.g. central statistical offices) and different level governments (e.g. local governments). Finally, it imposed many stringent requirements on firms who had to invest additional resources to comply with planning obligations (supply information, implement orders, procure inputs from and supply production to other firms as established by the plan) and to adapt to planning inconsistencies (e.g. between input allocation and production plans). Central planning was considered so system-specific, that it was the first and total victim of transformation in the economic domain. Other examples in point include the monobank system, state ownership, bureaucratisation of the economy, campaigns, money and prices, foreign

20 Cf. G. Grossman (1977).

${ }^{21}$ Cf. M. Kaser and J. G. Zielinski (1970). 
trade rates, political indoctrination and control of the economy, establishing investment priorities and revealing social preferences, controlling dispersed information and managing investment cycles.

The influence of systemic capital on organisational and cognitive processes and hence attitudes, strategies, choices, and goals, originates in specific forms of opportunistic behaviour, moral hazard and adverse selection. Agents (in particular the managers of enterprises) exploited, opportunistically, the difficulty that the central planner had in controlling the activity and properly measuring performance and outcome. They did this in ways such as hiding and distorting relevant information (e.g. on their actual production capacity) in order to receive lower plan objectives and make their implementation easier. ${ }^{22}$

Various features of the system made moral hazard an important problem. Plan indexes were rather aggregated and were often expressed in physical units and control could only concentrate on the formal respect of plan orders implementation. Bonuses were linked to the quantitative level of orders implementation, since there was no built-in way for planners, users and consumers to express dissatisfaction. In such circumstances, agents used their limited freedom to concentrate their effort on the simplest way of implementing the plan. Waste of resources and lack of technical progress were serious and inevitable consequences.

The process with the most negative impact was the selection of managers from the ranks of the Communist Party, therefore from among politically loyal people, who were usually not the most skilled people in running enterprises. However, in the centrally planned system what mattered was the careful implementation of plan orders, and so loyalty was the most important feature of a manager. As for firms, in a shortage economy no entry and exit mechanisms existed and firms utilised any input they could. The direct effect of this situation was that motivations and incentives to improve effort and quality were irrelevant. As a consequence, loyalty was at the disadvantage of efficiency in both the choice of goals and their implementation.

Opportunistic behaviour, moral hazard and adverse selection within the given circumstances of the Soviet-type system, particularly the classical variant of it, ${ }^{23}$ required the investment of resources to implement strategies and set up particular structures - and consequently system-specific assets - that made such strategy profitable to the individuals and the collective. At the same time, it required other resources that central planners had to invest in order to control and contrast such behaviour.

22 Agents made often use of the underground economy to this purpose. Interesting examples are presented by G. Mars and Y. Altman (1987).

23 Cf. for instance A. Nove (1977), in particular pp. 87-99. 


\section{STABILITY, EFFICACY AND OBSTACLES TO CHANGE}

Inefficent economic systems cause economic performance to be lower than could be achieved by using the same amount of actual or potential resources in the same context. One verifies this by comparing the performance of similar economies belonging in different economic systems. Systemic inefficacy takes different forms: increasing transaction and switching costs, weakening incentives to use existing resources and economic opportunities, preventing the generation of trials and the adaptation to changing environment, hindering and distorting processes of technical and institutional learning and discovery, hampering the diffusion of knowledge and information, causing systematic organisational errors, and precluding or discouraging the co-ordination of decision-making processes.

One should note that the great absolute level of investment in system-specific assets does not necessarily make the economic system inefficient. In fact, such investment may strengthen control, accelerate the modernisation of informal institutions, support competition or co-operation, favour the allocation of resources to more productive uses, foster greater employment of resources, and enlarge the market and reduce transaction costs. In these cases, the investment should be considered as an investment in economic development (e.g., in solving the reasons that prevent collective action). In fact, the great level of investment in system-specific assets was the condition for accelerated industrialisation, full employment and rapid growth rates.

This took place in restrictive circumstances, which included a simple structure of the economy and few simple goals that had absolute priority. These were the reconstruction and acceleration of production and industrialisation in post-revolution Soviet Union and other Central-East European countries. However, success crucially depended upon the willingness of the population to co-operate, even with personal sacrifice, to reach what was perceived as a common or superior goal, and the availability of additional (extensive) human and material resources. Under these circumstances, co-operation among agents replaced competition among them and made investment in system-specific assets quite effectual because such factors as common enthusiasm, expectations for a bright future, and ideology provided "shared mental models" 24 and behavioural strategies. These convinced actors to give priority to formal institutions over informal ones and allocated a substantial part of the cost of co-ordination outside the economy, e.g. to voluntary political activism. This produced a good co-ordination of individual actors' effort and stimulated actors to supply additional resources. In these cases

24 A. T. Denzau and D. C. North (1994). 
central planning could be effectual because it strongly reduced complexity and cost of contracts (indeed, central commands replaced contracts), concentrated information and simplified knowledge, and diffused them through vertical channels. If priority goals were sufficiently simple, their priority commonly accepted, and the outcome easily measurable, this institutional setting could substantially reduce transaction costs. This outcome compensates the high level of investment in system-specific assets.

At a certain point in the system history (the 60s), investment in system-specific assets started to become socially inefficient. However, the system remained stable until the $80 \mathrm{~s}$ in spite of recurring crises. The phenomenon that dominated in this second period can be defined as a systemic stationary situation, called "stasis". Stasis raises two questions: 1) Why did stasis take place? 2) How could an inefficient system be stable? My hypothesis is that changes that were implemented in the economic system and, consequently, system-specific assets were insufficient to allow the system to adapt to the great transformation in domestic economies and societies and in the external environment. Consequently, investment in system-specific assets became increasingly inefficient, and this was revealed in the increasing bureaucratisation, and the decreasing economic performance of the economy.

1) The success of the system in pursuing some basic goals drained unemployed resources and made the economy increasingly complex. The system was particularly well endowed with means for the rapid mobilisation and re-allocation of resources, and actors invested heavily in related assets. Stasis that followed was caused by two different sets of factors:

a) The progressive absorption of unemployed resources (plus the increasing burden of military expenditures) required additional investment in system-specific assets to mobilise residual unemployed resources through increasingly expensive and bureaucratised campaigns that missed by now popular support. This outcome required the allocation of a greater share of resources to investment in system-specific assets ${ }^{25}$ leaving a smaller share to investment in general assets.

b) Since the structure of the system was not changed, system-specific assets remained basically unchanged. However, the progress of the economy required new solutions (i.e. in the reallocation to more productive use and technical progress), hence investment in new system-specific assets were able to stimulate and

25 It is interesting to recall here CIA estimates in the $60 \mathrm{~s}$, that forecasted that large part of the Soviet population would have been employed in the central planning apparatus by the end of the century. 
support a different kind of development. Mismatch followed between the features of systemic assets and general assets. Investment in system-specific assets was less and less effectual.

Under these conditions, these economies were left without a growth engine and development, except for political and administrative intervention. In fact, technical progress - the much publicised and never materialised technical-scientific revolution - never became a priority factor of development in economies that lacked a proper economic system and hence incentives to that end. The decreasing effectiveness of investment in system-specific assets and the greater complexity of the economy in an unchanged economic system required the investment of a growing share of residual income. Moreover, investment became so relevant, complex, burdensome and costly as to constrain and hamper production. In fact, additional investment in system-specific assets - since it was mainly investment in control and enforcement - created new and substantial transaction costs and negative externalities for production mainly by increasing bureaucratic requirements. As a consequence, return to general investment was rapidly decreasing. This weakened incentives for such investment, requiring activation by political means (in particular, campaigns). Given systemic features, there were three possible answers to these problems, each of which was used in different proportions: a) reallocate resources from general investment (in particular, in the production of consumption goods) to investment in system-specific assets; b) obtain resources from abroad via trade deficits and credit; c) reform the economic system.

Reforms attempted to respond to these problems via progressive decentralisation and delegation of responsibility. However, investment in system-specific assets did not decrease substantially, because investment in that particular type of system-specific assets increased (that one could term as bargaining assets, due to the greatly increased role of "regulators", such as price formulas, wage determination schemes, and taxation). Actors became more interested in the results of their economic activity, but even more so in the effect of their bargaining activity over inputs allocation, the nature and value of regulators, and residual plan targets. Vertical distributive functions remained the most important co-ordination mechanism amidst a still rather soft budget constraint. ${ }^{26}$

2) The system was stable for a long time in spite of its inefficacy, lack of evolution, ${ }^{27}$ and the dissatisfaction of many actors. If one supposes that boundedly ra-

26 J. Kornai (1986), W. Swaan and M. Lissowska (1996).

27 In some countries of Central-Eastern Europe this lack of evolution was supported by the threat or the reality of foreign military intervention. 
tional actors are ready to invest valuable resources to pursue their individual economic advantage, one should conclude that the actors' dissatisfaction with the given system should convince them to act in order to change it. However, actors did not co-ordinate their activity nor any privileged group (in Olson's sense) appeared ${ }^{28}$ When change came, it resembled the features of punctuated equilibrium. ${ }^{29}$ It was initiated by the bold and risky activity of a group of central reformers around Gorbachev against the will of the population and economic actors at large. The system was centralised also in the governance of change.

My contention here is that actors opposed change just because they were (boundedly) rational and had invested resources in (old) system-specific assets. Stability of an inefficient system derives from different factors, along with high costs of change, that I will illustrate in section 5:

a) The existing system is more desirable from some positive or negative point of view. Here one can mention the role of ideology, the promise of social justice and equity, the historical circumstances that led to the victory of the Soviet-type system in those countries, economic backwardness, material and social advantages that the system offered (in terms of privileges, full employment, individual support and protection "from cradle to grave"), international isolation and external menace, overreaching power of the only party and the police, the threat of foreign military occupation and economic blackmail. These factors were linked to system-specific assets and led to the accumulation of systemic capital. Various variables among these have public good nature and their desirability is not strictly linked to the share of systemic capital that each individual actor owns. Hence, the stability of the existing system does not depend necessarily on the activity of particular interest groups or the existence of vested interests. Systemic capital creates a particular way of life.

b) The expected distributive outcome makes systemic transformation less desirable than the status quo. This produces an important case of collective action failure that may contribute to keep the system even when its inefficacy is revealed and the desire for change is socially shared. There are three reasons for this out-

28 The exception is obviously Solidarnosć in Poland, although this was more a mass movement than a privileged group.

29 The notion of punctuated equilibrium comes from evolutionary biology to denote that evolution occurs in rapid bursts over (geologically) short periods of time, and that there is relative stasis after the punctuational bursts. The analogy with the process I discuss here also comes from the punctuationsist conclusion that variational evolution takes place not only at the level of the individual and of the population, but at the level of species as well. Cf. A. Somit and S. A. Peterson (1992). It is easy to find an analogy between species in biology and the economic system. 
come: i) inter-temporal divergence between investment in system-specific assets and returns; ii) interpersonal and inter-organisational divergence in the proportion of investment and systemic capital over overall investment and capital; and iii) interpersonal and inter-organisational divergence in the allocation of opportunities, costs and advantages of systemic transformation. ${ }^{30}$

c) External factors prevent change. This was the case of all Soviet-type economies except larger ones (the Soviet Union and China) and Yugoslavia. This limit became particularly clear in the 1968 invasion of Czechoslovakia by the troops of the Warsaw Pact. Other examples were provided by Hungary and Poland in 1956.

\section{THE TRANSFORMATION OF THE ECONOMIC SYSTEM}

Stasis means that the system does not evolve spontaneously or its evolution is insufficient to adapt to environmental change. Under these conditions, the only possibility to come out of stasis is systemic transformation, i.e. rapid and radical modification of basic institutions and their co-ordination. In general, three sets of conditions are needed for starting systemic transformation. First, the appeal of the old system should decrease for whatever reason. Second, a new system - existing in reality, such as the capitalist system of the West, or just as a blueprint, such as socialism at the outbreak of the October Revolution - should be known as, or believed to be, superior and represent the target of systemic transformation. Third, there should exist an active agent of change, whom I define as a systemic entrepreneur. In Central and Eastern Europe all three conditions existed at the end of the 80 s.

A very important factor that explained economic reforms in the $60 \mathrm{~s}$ and the 80 s was the rapid fall of growth rates and the economic performance in Soviet-type economies. ${ }^{31}$ A set of other factors decreased the appeal of old systemic goals, introduced new ones, ${ }^{32}$ and increased the attractiveness of an alternative system, Western capitalism. However, reforms failed in promoting the evolution of the economic system, due to the systemic features mentioned in the previous section.

${ }^{30}$ Only this latter reason may depend on the presence of vested interests and interest groups.

31 Very useful readings are the books by M. Gorbachev (1987) and A. Aganbegyan (1988).

32 Among these, one can mention on the one hand the inability to catch up with the West, generalised and costly welfare systems with various rights attached to it, rapidly decreasing labour discipline, and on the other hand the growth of a new middle class, mitigation of external threat thanks to the policy of détente, progressive opening of those economies and societies to the world. 
The growing wedge between changing preferences and goals and inefficient and costly systemic means to pursue them, opened great opportunities that systemic entrepreneurs could take advantage of. Systemic entrepreneurs are individuals and organisations who see an opportunity to obtain individual or social gain (often in political terms) by decreasing the cost of running the system and making it more effectual. The general idea is to strongly reduce investment in (old) system-specific assets (e.g. by getting rid of central planning and political or police control over actors). This they do to free resources. A part of these resources could be invested in new system-specific assets, such as setting up the structures of, and financing the acquisition of competence for capital markets or for managing unemployment. This kind of investment, since it is addressed to support freedom of enterprise and competition, is considered to provide greater incentives to producers. Since investment in old system-specific assets was particularly great and investment in new system-specific assets is characterised by lower costs of controlthe latter being largely indirect and impersonal in a market economy and with the new system widely supported - such a shift leaves residual resources that can be invested in general assets. In this way, both absolute and relative return to general investment increases, thus strengthening incentives.

A necessary precondition for this to be true is a critical mass of investment in systemic transformation. This is analogous to an investment in a public good, since systemic transformation is indivisible and non-investors cannot be excluded from enjoying the fruits of successful change. A further feature of this investment is that (part of) its cost can be burdened to investment in general assets (and also in old system-specific assets if the initiators are powerful owners of systemic capital or if they are expropriated of the resources they owned). Investment in systemic transformation includes setting up new structures for reform (offices, committees and work groups), implementing experiments, organising political movement and parties, reorganising production, acquiring new skills, knowledge and information. Perestrojka in the Soviet Union offers an excellent example of this kind of investment. Investment in systemic transformation creates positive externalities for imitators (e.g. by weakening political control or opposition to change), thus reducing the investment that other actors have to make in order to adapt to the new system.

This investment also creates opportunities for owners of (old) systemic capital. Since the latter serves to control systemic governance before transformation, it gives the owners of systemic capital the necessary elements (e.g. crucial information and knowledge on ongoing processes, personal acquaintances) to influence the conditions among which systemic transformation unfold. Thus they are in an advantageous position for benefiting from investment in systemic transformation as imitators. They can also use the resources over which they have command, 
thanks to their ownership of (old) systemic capital, to implement a major investment in new system-specific assets or in general assets (see below for examples).

Because there remains resistance from old systemic capital, those who want to change the system have to invest a great deal of resources to do so. However, the resources invested to defend the old system (such as closer control over those who invested in system change and in general assets) could only be subtracted from investment in general assets. The greater cost of the economic system (in terms of greater control, weaker incentives, lower economic freedom and mobility of resources, etc.) increases further the burden over investment in general assets. Consequently, investment in both old system-specific assets and general assets becomes less profitable, thus depressing incentives to invest. These developments increase the probability that boundedly rational actors find an agreement on systemic transformation involving compensation for the losers - or else costs and advantages sharing.

However, such agreement can only be partial, because some actors have, or are convinced of having, great amounts of systemic capital that is bound to be lost if the system changes. In the case of systemic transformation, their only valuable asset is their ability to stop transformation. Rational systemic entrepreneurs promise to compensate losers in a credible way. Credible third-party enforcement is necessary to this end, because one of the parties loses retaliation power essential for the development and stability of spontaneous co-operation when systemic transformation is successful.

There is an important indirect way of paying such compensation. This happens at the start of systemic transformation, when owners of old systemic capital use their powerful position to accumulate general assets (e.g. ownership of privatised firms, sums of money deposited in foreign banks) before systemic entrepreneurs destroy the value of this capital. This investment is often financed by expropriating workers or citizens of property rights over firms, or expropriating firms of part of their liquid or material assets. These actions decrease the value that systemic entrepreneurs can appropriate and consequently the rate of return on their investment. Important cases of this kind of compensation in Central-Eastern Europe on the eve of transformation were the agreements reached at "round tables" between the government/party in power and the social opposition and "spontaneous" privatisation.

Transformation, by changing basic formal institutions and their co-ordination, dramatically changed the relative value of system-specific assets and investment therein. Some actors owned systemic capital that granted control over functions that became crucial during transformation. These were, e.g., those who were able to define and implement corporate laws dealing with the commercialisation of state-owned companies or decide when to privatise, which privatisation strategy 
and means to utilise and which companies to privatise. They usually enjoyed an abrupt increase of the value of their system capital, although they did not necessarily enjoy a proportional return to it.

This was also the case of the politically appointed managers of enterprises about to be privatised, and of some intellectual professions and political organisations. For instance the successful case of Komsomol (the Communist youth organisation in the Soviet Union) and their leader is particularly relevant in this sense. According to a survey in Russia some $61 \%$ of the new business élite is made of former managers, who were, like everybody else, Komsomol members. ${ }^{33}$

\section{SYSTEMIC ENTREPRENEURS AND TRANSFORMATION}

Systemic entrepreneurs are those agents of change and imitators who respond to the new conditions by investing in systemic transformation. ${ }^{34}$ It is the individual, group or social opportunities embodied in the systemic framework that give them the incentive for such action. Such incentive consists of the differential returns to either their own or to social, general or systemic capital. Reaching a critical mass of pressure to change overcomes the resistance of conservative actors, resistance that is based on old systemic capital. At this point in time, change happens in a way analogous to that depicted by the biological concept of punctuated equilibrium. When change is successful, many adaptation processes follow.

In Central and Eastern Europe there appeared different groups of systemic entrepreneurs: reformers, imitators, and investors in transformational distribution.

a) At the end of the $80 \mathrm{~s}$, reformers implemented a substantial part of investment in systemic transformation in the political heart of the system. In fact, systemic capital in this domain proved to be increasingly inefficient for the reasons seen in the previous section and failed to produce acceptable returns to its holders. ${ }^{35}$ The main actor was the group around Gorbachev, who acted as systemic entrepreneur and implemented the decisive investment in systemic transformation through

33 Cf. O. Kryshtanovskaya and S. White (1996), S. Johnson et al. (1999). In the political and government arenas, the presence of former nomenclature members is even greater.

34 Here the term entrepreneur is used in a fashion analogous to W. J. Baumol's (1993) to denote any actor whose non-routine activities are intended to innovate or change the economic system in a way that may be socially productive, but also destructive or rent-seeking, depending on the features of the existing economic system.

35 Intellectuals preceded political reformers in asking for systemic transformation. The best known such blueprint was the so-called Novosibirsk Report prepared by a team of social scientists co-ordinated by Abel Aganbegyan and Tatiana Zaslavskaya as early as 1981. Cf. NR (1984). 
glasnost and perestrojka. ${ }^{36}$ The government worked out and (half way) implemented plans that were openly designed to change the system. ${ }^{37}$

b) The owners of systemic capital who had no control over crucial functions of transformation resisted systemic transformation. However, resistance was most often only indirect and weak, since the relative value of their systemic capital dramatically decreased following the start of systemic transformation. The latter produced uncertainty over the future flow of returns to old systemic capital and decreased the value of flows. This shortened the time horizon and made conservative collective action difficult. In the Soviet Union such uncertainty increased enormously following the defeat of the attempted conservative coup in August 1991. Under these conditions, the action of systemic entrepreneurs fostered imitation and investment in systemic transformation until it reached a critical mass. Imitation destabilised the system well beyond the intent of original systemic entrepreneurs. Indeed, imitators had the fundamental role of diffusing systemic innovation, and introducing contrasting goals of transformation. This process went on until the value of old systemic capital vanished and the old system was destroyed. At the same time, reform activity in the Soviet Union and the statement that the Soviet Union would not interfere in domestic matters of other countries inflicted a deadly blow for the value of old systemic capital in the latter. This made the return to investment in systemic transformation particularly high, since a crucial component of system-specific assets was destroyed by the Soviet government.

c) Investment in systemic transformation by reformers, the activity of imitators, and the control that owners of old systemic capital had over crucial functions in transformation, modified the absolute and relative value of property rights over system-specific assets and the income flow that investment produced. This influenced the structure of relative prices, incentives, opportunities, and the bargaining power of actors. Some actors were able to influence the variability of particular attributes, thus influencing transformational distribution to their own advantage. These were, for instance, irregular or criminal actors, and owners of old systemic capital as politicians, managers or even workers who controlled functions that were crucial during transformation. There were various cases and examples of this kind of behaviour: the value-decreasing effect of the activity of the old system

36 For an excellent account of the evolution of Gorbachev's action cf. H. Smith (1990).

37 These plans included Academician and Deputy Prime Minister Abalkin's program for transition to a mixed planned market economy (November 1989), Prime Minister Ryzhkov's program for a regulated market economy (May 1990), Academician Shatalin's program for transition to a market economy, the so-called 500 days program (August-September 1990), the anti-crisis program approved by the Supreme Soviet and presented by Prime Minister Pavlov (April 1991), Yavlinsky's program for transition to be implemented in six and a half years. 
agents is well known in both market economies (e.g. the so-called "paradox of privatisation") and transformation economies (e.g. asset stripping, demonetisation, capital flight, interenterprise arrears). ${ }^{38}$

The kind of transformations that took place and the way in which they were implemented determined the distribution of the costs and advantages of systemic transformation. This was so because they changed the value of the flow of future returns and the costs of control. As a consequence, they altered the present value of general and systemic capital compared to the time before transformation and determined the features and costs of individual and collective adaptation processes. If the new distribution of property rights creates stronger incentives to the advantage of a more productive social and economic group, the just mentioned distribution of costs and advantages can be considered as a necessary condition for producing a more effectual economic system improving economic performance. The resources invested to reach this outcome should be seen as an investment in a more productive system. However, different actors may have asymmetric opportunities to influence outcomes. If such asymmetries derive from the allocation of old (pre-transformation) systemic capital, the outcome may be quite different and socially detrimental.

One important consequence of increased uncertainty from systemic transformation is that this decreases the actors' computational ability and influences their decision-making. In fact, the re-allocation of property rights on assets, together with the influence that different discount rates have on the behaviour of different actors, strongly influences the value of transformation to individual actors. The latter corresponds to the augmented flow of income that originates an increased net value of the actors' systemic and general capital. Clearly, actors who have longer perspective of active economic life have greater chances to obtain a positive net value. Alternatively, they can afford greater costs for investment in systemic transformation and adaptation.

Due to the changes that transformation introduces and that decrease the actors' computational ability, it is impossible at the beginning of transformation (when changes are implemented) to determine the value of property rights correctly in the economic system that will exist when transformation is over. A great amount of additional resources is needed to measure these new features, define and measure the rights that are transferred, enforce contracts and co-ordinate the choices

38 On the role of criminal actors during transformation cf. G. Grossman (1995). On interenterprise arrears in transformation economies cf. F. Coricelli (1996); on capital flight cf. A. Becchi and M. Mulino (2000); on demonetisation cf. OECD (2000); on asset stripping cf. M. B. Fox and M. A. Heller (1999) and B. Black et al. (1999). 
of actors. However, when the economic system changes, these co-ordinating and constraining functions are missing: old ones were destroyed or became ineffective and new ones are only developing. As a consequence, it is impossible to establish the actual flow of income that assets could produce in those circumstances, and it is difficult to enforce rights until the new system has been fully established.

This uncertainty shortens the actors' time horizon and promotes the choice of activities that promise return in the short run. The more radical is systemic transformation, the greater is the opportunity to profit from systemic transformation in order to gain rents in the form of rights, wealth, income and power. This outcome takes place through transformational distribution and requires an investment of resources to control information, exploit networks and collude with those who had invested successfully in systemic transformation - in particular in restructuring property rights - and bargain with a third party in charge of enforcement. The opportunity to gain in this way depends on the ownership of old systemic capital, in particular that type of systemic capital, which grants control over functions that becomes crucial during transformation. This means that transformational distribution is only compared to the ideal representation of the future economic system that systemic entrepreneurs have. Compared to the pre-transformation situation, distributive implications may be modest and concern more the nature of individually owned capital than its size.

Among the many examples in Central and Eastern Europe one should quote spontaneous privatisation that preceded transformation in Central Europe and insider privatisation in Russia, Ukraine, Serbia, Croatia, and Romania. Other relevant cases were those of former state administrators who entered privatisation agencies and of previous administrators or managers who were appointed as the head of offices or firms in view of their old systemic capital. Some of them established their own private businesses before abandoning their old jobs by investing resources that they subtracted from general assets they controlled (e.g. via asset stripping in the state company they controlled). ${ }^{39}$

A shortened time horizon and the crucial functions of the owners of old systemic capital make enforcement a fundamental component of transformation, just when this is all the more difficult and its outcome uncertain. This concerns in particular the role of the state: it is fundamental, but the old state structures - one crucial type of old system-specific assets - were disrupted and the new ones were just being established. Few actors are willing to invest resources in this fundamental undertaking (e.g. by paying taxes). Establishing the new structures of control and

39 Cf. the examples quoted by B. Dallago (1997). 
enforcement is a costly and time-consuming process, much longer than processes of transformational distribution. The spontaneous establishment of the structures for control and enforcement is unlikely, due to the prevalence of transformational distribution. Since actors are trying to gain new positions in the new system (to accumulate and increase the value of their capital), their interest to co-operate in establishing those structures is weak.

Given the above processes, there is no guarantee that wealth, income, power or prestige are captured by the socially most productive actors. In fact, when the system is changing, uncertainty over the working of the economic system and co-ordination increases dramatically. This makes selection criteria unclear and mutable, shortens the actors' time horizon and creates a great amount of contestable control over income streams, and assets. These variables form the quasi-rents of transformation that actors gain through transformational distribution. Under these circumstances, long-run economic calculation becomes very difficult or impossible, and rational actors try to capture some part of those quasi-rents by making use of their control over the transformation process. Since this control depends also on old systemic capital, which grants control over functions that are strategically important during transformation and on investment in transformational distribution, there is no guarantee of positive and spontaneous social productive outcomes. ${ }^{40}$ This raises the fundamental questions of policies and enforcement, that is, the effectiveness and efficiency of the state machinery and activity as a solution to the above problems. Therefore, rational actors interested in transformational distribution should look for the demise of the state. ${ }^{41}$

40 Such is, e.g. the idea of a market for institutions that S. Pejovich (1996) proposes. According to Pejovich, the market for institutions is a process, which allows individuals to select the rules of the game for their community. Through their voluntary interactions, individuals evaluate the prevailing rules, and identify and test new ones. The critical function of competitive markets is thus to encourage institutional innovations and adaptive behaviours. The market for institutions accomplishes this function by providing individuals with strong incentives and low transaction costs in seeking contractual agreements, which they perceive to be their best options. "Successes" and "failures" emerge from these voluntary interactions. The former are copied by others and eventually institutionalised. These institutional arrangements, which are produced within the system, are self-sustaining and in (continuous) competition with alternative rules.

${ }^{41}$ Cf. B. Dallago (2000b). 


\section{THE COSTS OF SYSTEMIC TRANSFORMATION AND THEIR CONSEQUENCES}

Asymmetries and uncertainty render investment in transformational distribution a low risk, an effective and individually rewarding way to avoid the public good trap typical of transformation processes and capture the positive externalities created by systemic entrepreneurs. Transformational distribution is not necessarily and entirely negative, though, in fact, it gives powerful incentives to imitators to support systemic transformation. However, it influences the features of the new system. What happens at this point resembles the process of path dependence as analysed in evolutionary economics. ${ }^{42}$ The latter shows that competitive selection of technology is path dependent when some forms of increasing returns to adoption are present. These can take different forms: increasing return to scale, dynamic learning-by-doing effects, network externalities, and spatial agglomeration effects.

We can find all these forms in the case of transformational distribution. I explained above that transformational distribution is made possible by investment in systemic transformation and consists mainly of owners of old systemic capital using the opportunities that systemic transformation opens up. They use their control over crucial functions to pursue quasi-rents. This process shows increasing returns, because the greater is the initial systemic capital, the greater the control and the higher the unitary returns may be in the form of quasi-rents. Dynamic learning-by-doing is also present, since knowing how the mechanism of transformational distribution works opens up additional opportunities. It may also lead to establish networks of actors and activities that strengthen their ability to control the process of transformational distribution, thus producing network externalities. The effect of transformational distribution may be particularly concentrated in certain regions or sectors/branches of the economy (e.g. privatisation of particular industrial branches) and thus may profit from spatial (or branch) agglomeration effects.

The final outcome may be that investors in transformational distribution become so powerful as to determine the process of systemic transformation and to give it their imprint. Since these actors use their (old) systemic capital to reach their goal, they likely favour the survival of old institutions (that would help them in reaching their goal) and old system-specific assets (such as political and bureaucratic networks), the monopolistic structure of industry, and protectionism. To the extent that they are successful, systemic transformation is path dependent,

${ }^{42}$ Cf. in particular W. Arthur (1994). 
that is, it takes place around systemic features that are at least closer - and often much closer - to those of the old system that the original transformational blueprint envisaged. In the case of transformation such systemic features may be, for example, lack of competition.

Behavioural processes favour this outcome. Disintegration of the old system and the time required for the development of the new one creates uncertainty, because the minimum co-ordinates for probability distribution of outcomes of actors' activity are missing. To overcome the problems of missing information and computational ability as consequences of systemic transformation, boundedly rational actors can use conservative strategies to adapt and pursue their own interest. These include strategies of simplification, the choice of the best option from among those they knew from their past experience and the adjustment of their behaviour to the previous criteria. There is much evidence that many actors chose this kind of strategy in Central and Eastern European countries, as in the case of the firms' extensive reliance on traditional business behaviour and networks, sometimes of an illicit or illegal nature. ${ }^{43}$

I stressed above that systemic transformation is also costly undertaking for individual actors. Indeed there are four types of costs connected to it that require investment in new system-specific assets. ${ }^{44}$ These are learning and measurement costs, enforcement costs, adaptation costs and transformation losses. Learning and measurement costs include acquiring proper articulated and tacit knowledge of the features and working system, collecting information on the new situation and the new positions of other actors, measuring the advantages and disadvantages of what is being produced and exchanged, and setting up new information systems and administrative offices. Enforcement costs comprise dismantling old monopolies, the setting up of new legal and administrative structures for contract enforcement, anti-monopoly offices and policies and preventing the defence of the old system privileges. Adaptation costs are the costs of those actions and structures necessary to take advantage of, or resist, redistribution of rights and assets, protect the new rights, specify contracts and restructure and improve governance in line with the new system, and develop new routines. Finally, transformation

43 Cf., for instance, W. Andreff (1996), I. Gurkov (1997). In general, this attitude was less pronounced in countries that reformed their economy earlier (such as Hungary and Poland) and much more relevant in countries that arrived unreformed to transformation and experienced various shocks (such as many post-Soviet countries). In fact, in the former group of countries the lengthy and somehow consistent process of reform reduced uncertainty, gave actors more time to adapt and reduced opportunities for transformational distribution. Hence individual reaction was less conservative. These factors mitigated path dependence.

44 Cf. B. Dallago (1996). 
losses are those that actors incur because of the disappearance or the reduction of the value of their old systemic capital, which in turn generates a flow of lower incomes for these same people. Indeed, skills become valueless, valuable positions and the bargaining powers deriving from them are lost, jobs are destroyed, and individuals are expropriated of property rights.

The importance of transformation costs goes well beyond their individual effect and strongly influences the outcome of transformation. Although these costs could be considered as the cost of investment in systemic transformation, and should be financed ex post by greater efficiency and lower transaction costs of economic activity in the new system, there is no guarantee that this be so. In fact, their existence strengthens the actors' conservative strategies that follow from uncertainty. In the particular case of transformation costs, actors try to avoid these costs or re-allocate them to other actors, comprising the state. These strategies are likely to produce conservative systemic path dependence as the solution that can minimise transformation costs and distributive conflict. The degree of "conservativeness" depends on starting conditions (in particular, the difference between the old and the new system), the strategy and policies of transformation, and external support.

Path dependence is a kind of adaptation to systemic transformation that reduces individual costs, but is likely to lead to a sub-optimal transformation outcome. A socially better alternative is to adopt a concerted co-operative strategy of transformation, including a pre-agreed allocation of costs and advantages, including the compensation of losers. Why do boundedly rational actors adapt to the individually costlier and socially less desirable strategy of transformation? There are four different reasons for this.

First, many factors (e.g. lack of previous experience, hope in external support, the prevalence of wrong theories of systemic transformation) lead actors to underestimate the level of transformation costs. Second, some actors (in particular, reformers and planners of transformation policies and managers of the most efficient enterprises) have long-term strategies in which transformation costs play the role of investments in a more productive system. Since these actors had previously invested in systemic transformation or in general capital whose return was depressed by costly control and enforcement, they are eager to avoid the actions and relative costs needed to defend their investment against enforcement in the old system and to obtain a return on that investment. Third, transformation is seen as a unique opportunity for rent-seeking, as in the cases of spontaneous privatisation, credit-for-loans, financial pyramids, illegal export of financial and natural resources, the many petty cases of arbitrage over imported goods, but also mass privatisation via free vouchers. Its costs are considered lower than the short-term advantages that the new system promises, usually via transformational distribu- 
tion, or they can be allocated to other actors. Fourth, the uneven allocation of transformation costs among actors creates advantages for those who have particularly important decision-making power (such as politicians, managers of enterprises and of privatisation agencies or the newly settled financial institutions, bankers and various professionals).

\section{CONCLUSION}

Investment in transitional distribution and transformation costs, given the uncertainty that investment in systemic transformation creates, make systemic transformation less profitable than their promoters expected it to be. This weakens incentives for systemic entrepreneurs to continue their effort and causes path dependence. Under these circumstances, path dependence is a rational response, which renders some specific solution less difficult and less costly and therefore more likely to prevail than others. Other factors strengthen the probability of path dependent transformation, including: sticky informal institutions, cognitive processes arising from previous investment in old system-specific assets, the activity of interest groups, network externalities, and increasing returns to scale.

I mentioned above that long-run reforms fostering evolutionary adaptation are a preferable strategy to the transformation of economic systems. However, these may encounter unsurmountable obstacles: in this case systemic transformation is the only option to modernise the economic system, in the sense of adapting it to environmental transformations. The problems mentioned above highlight that, in this latter case, spontaneous processes are insufficient to guide systemic transformation and stress the necessity for governance of these processes. Specific structures (such as roundtables) were set up in transformation countries to govern systemic change and the allocation of costs and gains. However, such structures missed the power and instruments necessary to enforce general agreements or decisions. Liberalisation was introduced to allow for the development of new actors and bring in competition. Both were partially successful - nor could it be otherwise -, but only in countries that had a relatively long history of reform and "socialist" liberalisation, namely in Central Europe.

Systemic transformation is a definitely more complex undertaking than was believed by most scholars and policymakers at the beginning. It also includes many traps. For instance, there is no doubt that the state is a fundamental structure to reduce uncertainty, extend the actors' time horizon, and govern the allocation of costs and advantages during transformation. It is only within this framework that spontaneous process could reward socially productive actions. However, the state is a double-edged instrument, since it also gives opportunities and incentives to in- 
vest an excessive share of resources in system-specific assets, and can weaken incentives and opportunities to invest in general assets. The role of the state, therefore, should be one of establishing the conditions for an efficient market for institutions to develop. This may require finding solutions to the problems of systemic uncertainty and of asymmetric starting positions in the market for institutions. One should also remember that the state itself is in transformation. This means that the state is weakened in its traditional functions or unable to implement them and its capabilities to pursue new ones are insufficient. A necessary precondition for an efficient market for institutions is to invest in rebuilding the state and enforcing its autonomy and establish its accountability and democratic control.

Another trap lies in liberalisation. Although important and in the long run necessary, plain liberalisation is not enough, and may even be counterproductive. Actors bring into the new system their old behaviour, as a consequence of their old systemic capital. Liberalisation and competition do change the economic environment, but actors that already existed in the old system may be hard to transform. Under these circumstances, denationalisation may fail in pursuing competition and efficiency. Foreign capital may do the job, but only in relatively small countries. Moreover, it is not certain that foreign capital acts in the interest of the country. Ambitious managers may properly restructure firms they got through spontaneous privatisation and improve their performance. However, all this is hardly enough if the capital and entrepreneurial basis of the economy remains circumscribed to those that already were running the firms in the old system. It is particularly for this reason that the establishment of new firms, usually small and medium in size, is important. However, in a transformation economy these firms are usually in a disadvantageous position. If not properly supported and stimulated, they may easily end up as a "survival sector".

All this stresses that systemic transformation is a complex undertaking that requires proper co-ordination among different processes. The new system, to work efficiently, must include this co-ordination. In evolutionary processes, this outcome takes place through continuous trial and error. This is not so in the case of a punctuated-like transformation. Here conditions must be created to allow for co-ordination to take place progressively. Having this point clear and acting accordingly may avoid the inevitable result that co-ordination is imposed by facts, probably at a lower level of efficacy.

\section{ACKNOWLEDGEMENTS}

The author is grateful to Gregory Grossman and George Breslauer (University of California at Berkeley), Oliver Williamson, Pablo Spiller, Witold Jerzy Henisz, Aija Leiponen, Patrick S. 
Moreton, and Dimitry Rtischev (Haas School of Business, University of California at Berkeley), the participants to two seminars at the Institute for Economic Research, Hitotsubashi University, the Slavic Research Center, Hokkaido University, and two anonymous referees for helpful comments on previous versions of this paper. However, any responsibility for errors and weakness of analysis remains solely with the author.

\section{REFERENCES}

Aganbegyan, A. (1988): La perestrojka nella economia (Perestroika in the Economy). Milan: Rizzoli.

Andreff, W. (1996): Corporate Governance of Privatized Enterprises in Transforming Economies: A Theoretical Approach. MOCT-MOST, 6: 2, pp. 59-80.

Arthur, W. B. (1994): Increasing Returns and Path Dependence in the Economy. Ann Arbor: University of Michigan Press.

Baumol W. J. (1993): Entrepreneurship, Management, and the Structure of Payoffs. Cambridge, Mass.: The MIT Press.

Becchi, A. and Mulino, M. (2000): Fughe di capitali e riciclaggio di capitali sporchi: qualche riflessione sul caso della Federazione Russa. Rome: UIC.

Berliner, J.S. (1999): The Economics of the Good Society. The Variety of Economic Arrangements. Oxford: Blackwsell.

Black, B., Kraakman, R. and Tarassova, A. (1999): Russian Privatization and Corporate Governance: What Went Wrong? Stanford Law School, John M. Olin Program in Law Economics, Working Paper No. 178, September.

Coricelli, F. (1996): Inter-enterprise Arrears in Economies in Transition: Analytical, Empirical and Policy Issues. In: Dallago, B. and Mittone, L. (1995) (eds): Economic Institutions, Markets and Competition. Centralisation and Decentralisation in the Transformation of Economic Systems. Cheltenham: Edward Elgar, pp. 291-318.

Dallago, B. (1996): Investment, Systemic Efficiency and Distribution. Kyklos, 49: 4, pp. 615-641.

Dallago, B. (1997): The Economic System, Transition and Opportunities for Entrepreneurship. In: Entrepreneurship and SMEs in Transition Economies. Paris: LEED/OECD, pp. 103-124.

Dallago, B. (ed.) (1999): Convergence and Divergence of Economic Systems. Economic Systems, 23: 2, pp. 127-176.

Dallago, B. (2000a): The Organisational and Productive Impact of the Economic System. The Case of SMEs. Small Business Economics, 15: 4, pp. 303-319.

Dallago, B. (2000b): The State and the Transformation of Economic Systems. Paper presented at the Second Workshop of The International Center for the Study of East Asian Development, Kitakyushu City and Nomura Research Institute, Budapest, November 24-25.

Denzau, A. T. and North, D. C. (1994): Shared Mental Models: Ideologies and Institutions. Kyklos, 47: 1, pp. 3-31.

Fox, M. B. and Heller, M. A (1999): Lessons from Fiascos in Russian Corporate Governance. University of Michigan, Law School, William Davidson Institute.

Gardner, S. H. (1998): Comparative Economic Systems. 2nd ed., Fort Worth, TX: The Dryden Press. Gerschenkron, A. (1968): Continuity in History and Other Essays. Cambridge, Mass.: The Belknap Press.

Gorbachev, M. (1987): Perestroika. New Thinking for our Country and the World. New York: Harper \& Row.

Grossman, G. (1974): Economic Systems. 2nd ed., Englewood Cliffs, New York: Prentice Hall.

Acta Oeconomica 51 (2000/2001) 
Grossman, G. (1977): The "Second Economy" of the USSR. Problems of Communism, 26, pp. $25-40$.

Grossman, G. (1995): Origins of Russian Organized Crime. Paper presented at the Fifth Trento Workshop on Privatization and Distribution. The Consequences of Privatization of State Ownership for Distribution and Chances for Development, Department of Economics, University of Trento and European Association for Comparative Economic Studies, Trento, 3-4 March.

Gurkov, I. (1997): Russian Enterprises. Adaptation to New Economic Realities. MOCT/MOST, 7: 2, pp. $57-89$.

Hoen, H. W. (1998): The Transformation of Economic Systems in Central Europe. Cheltenham: Edward Elgar.

Johnson, S., McMillan, J. and Woodruff, C. (1999): Property Rights, Finance and Entrepreneurship. Working Paper 43, December, London: European Bank for Reconstruction and Development.

Kaser, M. and Zielinski, J. G. (1970): Planning in East Europe. Industrial Management by the State. London: The Bodley Head.

Koopmans, T. and Montias, J. M. (1971): On the Description and Comparison of Economic Systems. In: Eckstein, A. (ed.): Comparison of Economic Systems: Theoretical and Methodological Approaches. Berkeley: University of California Press.

Kornai, J. (1980): Economics of Shortage. Amsterdam: North-Holland.

Kornai, J. (1986): The Hungarian Reform Process: Visions, Hopes and Reality. Journal of Economic Literature, December, pp. 1687-1737.

Kornai, J. (1992): The Socialist System. The Political Economy of Communism. Princeton: Princeton University Press.

Kornai, J. (2000): Ten Years after "The Road to a Free Economy": The Author's Self-Evaluation. Paper prepared for the World Bank Annual Bank Conference on Development Economics, April 18-20, Washington, D.C.

Kryshtanovskaya, O. and White, S. (1996): From Soviet Nomenclature to Russian Élite. Europe-Asia Studies, 48: 5, pp. 711-733.

Li, D. (1996): A Theory of Ambiguous Property Rights in Transition Economies: The Case of the Chinese Non-state Sector. Journal of Comparative Economics, 23, pp. 1-19.

Mars, G. and Altman, Y. (1987): Case Studies in Second Economy Production and Transportation in Soviet Georgia. In: Alessandrini, S. and Dallago, B. (eds): The Unofficial Economy. Consequences and Perspectives in Different Economic Systems, Aldershot: Gower, pp. 197-217.

North, D. C. (1990): Institutions, Institutional Change and Economic Performance. Cambridge: Cambridge University Press.

Nove, A. (1977): The Soviet Economy. London: George Allen \& Unwin.

NR (1984): The Novosibirsk Report. Survey, 28: 1, pp. 83-108.

OECD (2000): OECD Economic Survey 1999-2000s. Russian Federation. Paris: OECD.

Pejovich, S. (1996): The Market for Institutions vs. the Strong-Hand-of-the-State: The Case of Eastern Europe. In: Dallago, B. and Mittone, L. (eds): Economic Institutions, Markets and Competition. Centralisation and Decentralisation in the Transformation of Economic Systems. Cheltenham: Edward Elgar, pp. 111-126.

Pejovich, S. (1998): Toward a Theory of the Effects of the Interaction of Formal and Informal Institutions on Social Stability and Economic Development. Paper presented at the Conference on Formal Institutions and Informal Arrangements in Transformation Societies, University of Potsdam, Germany, October 7-9. 
Simon, H. A. (1990): Bounded Rationality. In: Eatwell, J., Milgate, M. and Newman, P. (eds): The New Palgrave. A Dictionary of Economics: Utility and Probability. New York: W.W. Norton, pp. $15-18$.

Smith, H. (1990): The New Russians. New York: Random House.

Somit, A. and Peterson, S. A. (eds) (1992): The Dynamics of Evolution. The Punctuated Equilibrium Debate in the Natural and Social Sciences. Ithaca: Cornell University Press.

Swaan, W. and Lissowska, M. (1996): Capabilities, Routines, and East European Economic Reform: Hungary and Poland before and after the 1989 Revolutions. Journal of Economic Issues, 30: 4, pp. 1031-1056.

Williamson, O. E. (1985): The Economic Institutions of Capitalism. Firms, Markets, Relational Contracting. New York: The Free Press. 